\title{
FÓSFORO DA BIOMASSA MICROBIANA E ATIVIDADE DE FOSFATASE ÁCIDA APÓS APLICAÇÃO DE FOSFATO EM SOLO NO SISTEMA PLANTIO DIRETO(1)
}

\author{
E. CONTE ${ }^{(2)}$, I. ANGHINONI (3) \& D. S. RHEINHEIME ${ }^{(4)}$
}

\begin{abstract}
RESUMO
A atividade de fosfatases e a biomassa microbiana são fundamentais no ciclo do fósforo no solo e no seu fornecimento às plantas. Este trabalho analisa os reflexos da aplicação de fósforo na atividade de fosfatase áci da e no acúmulo de fósforo na biomassa microbiana em solo no sistema plantio direto. Em janeiro de 2000, coletaram-se amostras da camada de 0-10 cm nos tratamentos de doses acumuladas de $0,130,180,260,360,540,720,980$ e $1.240 \mathrm{~kg}^{-1} \mathrm{de}_{2} \mathrm{P}_{2} \mathrm{O}_{5}$ em seis anos de cultivo de um experimento em Latossolo Vermelho distroférrico típico muito argiloso. Coletaram-se também amostras do solo sob mata nativa, em área próxima ao experimento. Determi naram-se os teores de fósforo na biomasssa mi crobiana, a ati vidade de fosfatase ácida, o fósforo total, orgânico e disponível, e o carbono orgânico total. 0 solo sob mata nativa apresentou os maiores valores de fósforo microbiano, de atividade de fosfatase ácida e de fósforo orgânico. A ati vidade de fosfatase áci da não foi influenciada pela adição de fosfato. $O$ fósforo contido na biomassa microbiana aumentou com a aplicação recente de fosfato e não foi influenciado pelo fósforo do solo de aplicações anteriores.
\end{abstract}

Termos de indexação: fosfato solúvel, fosfatase ácida, biomassa microbiana, plantio direto.

(1) Parte da Tese de Mestrado do primeiro autor, apresentada à Universidade Federal do Rio Grande do Sul - UFRGS. Financiado pelo CNPq/APQ-Pronex. Recebido para publicação em junho de 2001 e aprovado em setembro de 2002.

(2) Engenheiro-Agrônomo, Universidade Federal do Rio Grande do Sul - UFRGS. Caixa Postal 776, CEP 91540-000 Porto Alegre (RS). E-mail: e.d.conte@zipmail.com.br

(3) Professor do Departamento de Solos, UFRGS. Bolsista CNPq. E-mail: ibanghi@ufrgs.br

(4) Professor do Departamento de Solos, Universidade Federal de Santa Maria - UFSM. Caixa Postal 221, CEP 97105-900. Santa Maria (RS) Bolsista CNPq. E-mail: danilo@ccr.ufsm.br 


\author{
SUMMARY: PHOSPHORUS IN THE MICROBIAL BIOMASS AND ACID \\ PHOSPHATASE ACTIVITY BY PHOSPHATE APPLICATION IN \\ SOIL UNDER NO-TILLAGE SYSTEM
}

\begin{abstract}
Microbial bi omass and phosphataseactivity areessential for phosphorus dynamics in thesoil and its supply for plants. This research determines the effects of phosphateapplication on phosphorus accumulation in microbial biomass and on acid phosphataseactivity in soil under no-till system. In J anuary 2000, samples of the 0-10 cm soil layer were collected from the treatments of accumulated applicati on rates $(0,130,180,260,360,540,720,980$ and $1,240 \mathrm{~kg} \mathrm{ha}^{-1}$ of $\mathrm{P}_{2} \mathrm{O}_{5}$ ) during thesix experimental years in a very clayey Rhodic Hapludox (Oxisol). Soil samples under native forest cl ose to the experiment were also collected. Phosphorus contents in the microbial biomass, total, organic and available phosphorus, acid phosphataseactivity, and total organic carbon weredetermined. Thesoil under native forest presented the highest values for all measured attributes. The enzyme activity was uninfluenced by phosphate addition. The amount of phosphorus stored in the microbial biomass increased on account of the last phosphate addition, but remained unaffected by phosphorus in thesoil from previous additions.
\end{abstract}

Index terms: soluble phosphate, acid phosphatase, microbial biomass, no-till.

\section{INTRODUÇÃO}

Os sistemas naturais, como florestas e campos nativos, conseguem auto-sustentar-se sem adição de fertilizantes fosfatados, mesmo em sol os com baixa disponibilidade de fósforo (P). Nesses sistemas, o P disponível é controlado pela ciclagem de $\mathrm{P}$ orgânico (Po), tendo como componente essencial a biomassa microbiana (Guggenberger et al., 1996). Os microrganismos eas raízes de plantas transformam Po em fósforo inorgânico $(\mathrm{Pi})$ disponível no solo através da exclusão de enzimas, globalmente denominadas fosfatases.

Quando os solos são cultivados, diminuem os teores de matéria orgânica e de Po pela al teração na vegetação, mobilização e arejamento do solo, com conseqüente aumento da atividade microbiana e retirada de nutrientes (Magid et al., 1996). A contribuição do Po no suprimento de $P$ às plantas é insuficiente para el evados níveis de rendimento das culturas comerciais, e as adições de fertilizantes fosfatados resultam em aumento da biomassa produzida, com reflexos econômicos acentuados.

Percebe-se que adição de fertilizantes fosfatados aos sol os tem resultado em aumento nos teores de $P$ armazenados na biomassa microbiana (Saffigna et al., 1989). Este aumento de fósforo na biomassa microbiana (Pm) foi verificado mesmo em solos argilosos (Lukito et al., 1998), o que demonstra a eficiência dos mi crorganismos na competição com os colóides inorgânicos do solo pelo $\mathrm{P}$ adicionado. Por outro lado, com o aumento da disponibilidade de Pi no solo deve diminuir a importância das fosfatases no suprimento de Pi (Clarholm, 1993), uma vez que as plantas sãoatendidas em sua demanda por fósforo.
No sistema plantio direto (SPD), o nãorevolvimento e a constante cobertura do solo permitem o acúmulo de material orgânico na superfície, o qual fornece energia, carbono eelétrons para o crescimento e desenvolvimento dos microrganismos e, juntamente com as menores flutuações de temperatura e umidade, geralmente contribuem para o aumento da biomassa e da atividade microbiana (Saffigna et al., 1989). A matéria orgânica também protege as enzimas da decomposição (Harrison, 1983). Além disso, no plantio direto, percebe-se maior atividade de fosfatases em relação ao preparo convencional (Doran, 1980), porém, quando se adicionam fertilizantes fosfatados solúveis, a alta disponibilidade de Pi pode inibir a atividade de fosfatases. Mesmo assim, no SPD, a biomassa poderá atuar como dreno do $\mathrm{P}$ adicionado, deixando-o disponível por mais tempo às plantas.

O presente trabalho determina os reflexos da aplicação de doses crescentes de fertilizante fosfatado na ativi dade de fosfatase áci da e no fósforo contido na biomassa mi crobiana de sol o no sistema plantio direto.

\section{MATE RIAL E MÉTODOS}

Utilizaram-se amostras de solo do experimento "Calibração de doses de fósforo em sistema plantio direto", realizado pela Cooperativa Tritícola Santo Ângel o(COTRISA - Santo Ângelo, RS) em convênio com a FUNDACEP, Cruz Alta (RS). O experimento foi instalado no inverno de 1994 em área que vinha sendo cultivada há Iongo tempo sob preparo convencional, seguida de cultivo por três anos sob 
SPD, num Latossolo Vermelho distroférrico típico muito argiloso. A correção da acidez do solo foi realizada, juntamente com a instalação do SPD na área, para el evar opH do solo até 6,0 (SMP pH 6,0). Os tratamentos consistiram de diferentes doses e épocas de aplicação de fosfato solúvel ao solo. Cultivaram-se aveia (94), soja (94/95), nabo forrageiro(95), milho (95/96), aveia + nabo forrageiro (96), milho(96/ 97), aveia (97), soja (97/98), aveia + nabo forrageiro (98), milho (98/99), trigo (99) e soja (99/00). As adubações com nitrogênio e potássio foramas mesmas (CFSRS/SC, 1995) para todos os tratamentos e para as diferentes culturas. O delineamento experimental utilizado foi o de blocos casualizados com parcelas subdivididas em faixas, com três repetições.

Coletaram-se, em janeiro de 2000, amostras do solo dos tratamentos 0, 30, 60, 90 e $120 \mathrm{~kg} \mathrm{ha}^{-1} \mathrm{ano}^{-1}$ de $\mathrm{P}_{2} \mathrm{O}_{5}$, aplicados no inverno sem reposiçãono verão; dos tratamentos com reposição de 1/3 e 2/3 da recomendação para a cultura de verão sobre 0 (zero) $\mathrm{kg} \mathrm{ha}^{-1}$ de $\mathrm{P}_{2} \mathrm{O} 5$ no inverno e dos tratamentos com reposição de 2/3 e 4/3 da recomendação para a cultura de verão sobre $120 \mathrm{~kg} \mathrm{ha}^{-1} \mathrm{ano}^{-1}$ de $\mathrm{P}_{2} \mathrm{O}_{5}$ no inverno. Nos seis anos de cultivo, isso representou doses acumuladas de $0,130,180,260,360,540,720$, 980 e $1.240 \mathrm{~kg} \mathrm{ha}^{-1}$ de $\mathrm{P}_{2} \mathrm{O}_{5}$. As amostras de solo foram retiradas na profundidade de $0-10 \mathrm{~cm}$, nos três blocos, compostas de quatro monolitos de solo $(5 \times 20 \times 10 \mathrm{~cm}$; comprimento $\times$ largura $\times$ profundidade) col etados em minitrincheiras. As amostras de sol o foram col etadas noestádioV3 de desenvol vimento da soja ( 3 o nó trifólio completamente desenvolvido acima do 2 o nó), aproximadamente 40 dias após a última aplicação do fertilizante fosfatado. Col etaram-se, da mesma forma, amostras do sol o sob mata nativa, em área próxima ao experimento.

Para a análise de fosfatase áci da, após homogeneização da amostra composta por ocasião da col eta no campo, aproximadamente $10 \mathrm{~g}$ de solo for am congel ados em nitrogênio líquido até o momento da análise. O restante do sol o foi seco ao ar, peneirado em malha de $1 \mathrm{~mm}$ e acondicionado em potes plásticos. Na amostra de solo mantida sob baixa temperatura, foi determinada a atividade de fosfatase ácida (fosfomonoesterases), segundo método de Tabatabai \& Bremner (1969), assim descrita, de forma resumi da: incubação de $1 \mathrm{~g}$ de solo com a mistura de $1 \mathrm{~mL}$ dep-nitrofenyl fosfato, $4 \mathrm{~mL}$ de tampão modificado com pH 6,5 (MUB, pH 6,5) e $0,25 \mathrm{~mL}$ de tolueno. A incubação foi realizada por 1 hora a $37^{\circ} \mathrm{C}$ em erlenmeyers fechados de $50 \mathrm{~mL}$, seguida da adição del $\mathrm{mL} \mathrm{CaCl}_{2}\left(0,5 \mathrm{~mol} \mathrm{~L}^{-1}\right)$ e $4 \mathrm{~mL}$ de $\mathrm{NaOH}\left(0,5 \mathrm{~mol} \mathrm{~L}^{-1}\right)$, e filtragem da mistura em papel Whatman $\mathrm{n} 02 \mathrm{v}$. A atividade da fosfatase foi obtida pela quantificação espectrométrica a 400 ๆm do p-nitrofenol liberado na mistura filtrada. Efetuou-se a análise em triplicata para cada uma das três repetições do campo.

No solo seco e peneirado, determinaram-se o carbono orgânico total, por combustão úmida, e o $\mathrm{P}$ disponível (Mehlich-1), segundoTedesco et al. (1995). O Po foi quantificado pel o método de ignição (Olsen \& Sommer, 1982), o P total após extração com $\mathrm{H}_{2} \mathrm{O}_{2}$ a quente (Rheinheimer et al., 2000) e o teor defósforo microbiano (Pm) após incubação do solo por 40 dias na temperatura de $25^{\circ} \mathrm{C}$ pel o método de Hedley \& Stewart (1982), adaptado por Rheinheimer et al. (2000). Esse método contempla a extração do Pi disponível com resina antes do processo de fumigação-extração com $\mathrm{NaHCO}_{3}$ (Brookes et al., 1982) e ajuste na capacidade de adsorção de $P$ pelo solo (Morel et al., 1996).

Para avaliar o efeito das diferentes doses de fósforo adicionadas, os resultados foram submeti dos à análise de variância e de regressão polinomial, com significância mínima de 5 \%. Efetuaram-se correlações lineares simples entre as variáveis analisadas. Correlações com $\mathrm{P}<0,05$ foram consideradas significativas.

\section{RESULTADOS E DISCUSSÃO}

Os teores de $\mathrm{Pm}$ variaram de 8,7 a $25,0 \mathrm{mg} \mathrm{kg}^{-1}$ (Figura 1 ), enquanto os teores de $\mathrm{P}$ disponível (Mehlich-1) variaram de 3,2 a 40,0 $\mathrm{mg} \mathrm{kg}^{-1}$ (Figura 2), respectivamente, para o tratamentotestemunha eaplicação de $1.240 \mathrm{~kg} \mathrm{ha}^{-1} \mathrm{deP}_{2} \mathrm{O}_{5}$. No entanto, a configuração das curvas difere substancialmente entre eles. Enquanto os valores do $\mathrm{P}$ disponível ajustaram-se a uma função quadrática $\left(r^{2}=0,95: P<0,05\right)$, os valores de $\mathrm{Pm}$ ajustaram-se a duas funções quadráticas $\left(r^{2}=0,83\right.$ e 0,86 , respectivamente; $\mathrm{P}<0,05$ ). Neste caso, a aplicação anual de $P$ somente nas culturas de inverno (doses acumuladas de 0 a $720 \mathrm{~kg} \mathrm{ha}^{-1}$ de $\mathrm{P}_{2} \mathrm{O}_{5}$ ) proporcionou aumentos relativamente pequenos de $\mathrm{Pm}$ (de 9,4 para 11,9 $\mathrm{mg} \mathrm{kg}^{-1}$ ), em relação à sua aplicação nas culturas de verão. Nestas, o maior aumento ocorreu tanto nas doses equivalentes a 1/3 e 2/3 do val or de reposição (doses acumuladas de 260 e $520 \mathrm{~kg} \mathrm{ha}^{-1}$ de $\mathrm{P}_{2} \mathrm{O}_{5}$ ) sobre as parcelas que não receberam $\mathrm{P}$ (de 9,4 para $21,4 \mathrm{mg} \mathrm{kg}^{-1}$ ), como nas doses equivalentes a $2 / 3 \mathrm{e}$ $4 / 3$ do valor de reposição sobre as parcelas que receberam $120 \mathrm{~kg} \mathrm{ha}^{-1}$ de $\mathrm{P}_{2} \mathrm{O}_{5}$ no inverno (de 11,9 para 25,0 mg kg${ }^{-1}$ ). Os maiores valores de P m foram superiores ao do solo sob mata nativa, que era de 13,6 $\mathrm{mg} \mathrm{kg}^{-1}$ (Figura 1).

Acredita-se que a maior incorporação de fósforo na biomassa microbiana se deva à combinação da adição mais recente do fertilizante fosfatado com o período de grande disponibilidade de carbono dos resíduos da cultura anterior. Chauhan et al. (1979) observaram aumentos no Pm com a adição de gramínea, celul osee, ou, fertilizante fosfatado ao sol o e posteri or diminuição do Pm com o tempo da adição. Portanto, o aumento do $\mathrm{Pm}$ parecetemporário, o que poderia explicar os maiores valores de $\mathrm{Pm}$ nas parcelas com aplicações mais recentes de fosfato. 


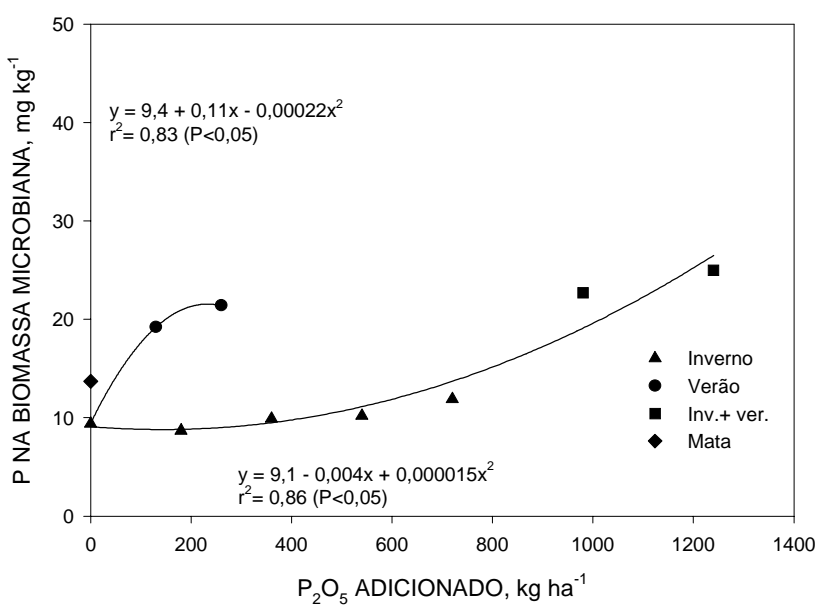

Figura 1. Teor de fósforo armazenado na biomassa microbiana na camada de $0-10 \mathrm{~cm}$ de um Latossolo Vermelho distroférrico típico, considerando diferentes doses e épocas de aplicação de fosfato solúvel, cultivado no sistema plantio direto.

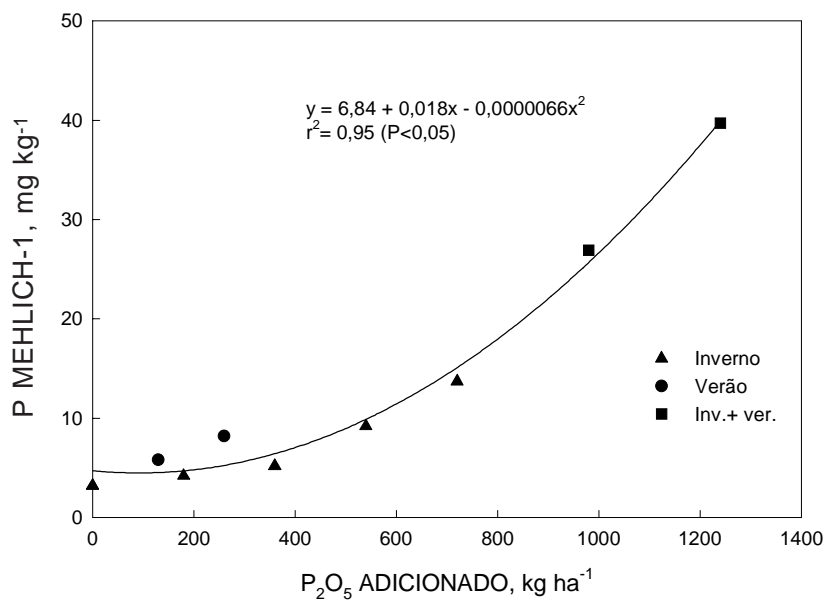

Figura 2. Fósforo disponível (Mehlich-1) na camada de $0-10 \mathrm{~cm}$ de um Latossolo Vermelho distroférrico típico, considerando diferentes doses e épocas de aplicação de fosfato solúvel, cultivado no sistema plantio direto.

A adição de apenas $20 \mathrm{~kg} \mathrm{ha}^{-1}$ de $\mathrm{P}_{2} \mathrm{O}_{5}$ (1/3 da manutenção) no cultivo da soja, cultura presenteno momento da coleta de amostra, contribuiu para valores de Pm de até 19,2 $\mathrm{mg} \mathrm{kg}^{-1}$ (Figura 1 ). Considerando que o Pm na testemunha, sem adição de fosfato, era de 9,4 $\mathrm{mg} \mathrm{kg}^{-1}$, verificou-seincremento de aproximadamente o dobro detectado, quando houve adição dessa dose de P. Mesmo que todo o fertilizante adicionado na última aplicação tivesse sido incor porado na biomassa microbiana, esse valor de Pm (19,2 $\left.\mathrm{mg} \mathrm{kg}^{-1}\right)$ teria de ser menor. Portanto, parece que, além do efeito temporário da aplicação do fosfato, o aumento de $\mathrm{P}$ no solo proveniente de aplicações anteriores no verão leva ao aumento da quantidade de $\mathrm{P}$ imobilizado na biomassa microbiana.

O aumento do Pm com a adição $\mathrm{P}$ ao solo já foi citado em vários trabalhos (Saffigna et al., 1989; Seeling \& Zasoski, 1993; Guerra et al., 1995; Lukito et al., 1998). A parte do Pi que é incorporada à biomassa microbiana constitui fonte potencial de $P$ disponível às plantas, por ser considerada uma fração lábil da matéria orgânica (Tate, 1984).

A diferença nos teores de Pm de 15,2 $\mathrm{mg} \mathrm{kg}^{-1}$, na mata nativa, para 9,4 $\mathrm{mg} \mathrm{kg}^{-1}$, no sol o cultivado sem adi ção de P (Figura 2), está em concordância com a diferença nos teores de Poe COT (Quadro 1). O teor de Po foi relativamente al to no solo de mata nativa, embora o teor disponível (Mehlich-1) tenha sido baixo e similar à situação de cultivo sem aplicação deP nos últimos seis anos (Figura 2). A diminuição dos teores Po na área cultivada relaciona-se com a diminuição do teor de carbono orgânico, comparado à mata nativa (Quadro 1).

Resultados obtidos por Pottker (1977) demonstraram perdas próximas a $50 \%$ do estoque de matéria orgânica de solos de mata ou campo nativo da região do Planalto e Missões do RS pelo cultivo do sol o por 10-15 anos nosistema convencional, que incluía lavração e gradagem duas vezes ao ano equeima de resíduos na cultura detrigo na sucessão trigo-soja, ou manutenção das áreas em pousio no inverno, tal como ocorreu anteriormente na área do experimento. Outros autores também têm demonstrado a diminuição nos teores de Po pelo cultivo intenso do solo (Tiessen et al., 1983; Bowman et al., 1990; Fernandes et al., 1998; Zhang et al., 1999).

A atividade de fosfatase ácida no solo sob mata nativa foi elevada ( $1.504 \mu \mathrm{g}$ de $\rho$-nitrofenol $\mathrm{h}^{-1} \mathrm{~g}^{-1}$ de solo), correspondendo cerca de 2,5 vezes à do solo cultivado (600 $\mu \mathrm{g}$ de $\rho$-nitrofenol $\mathrm{h}^{-1} \mathrm{~g}^{-1}$ de solo) (Quadro 2), graças, provavelmente, aos menores teores de Po (Ross et al., 1995). Maior atividade de

Quadro 1. Fósforo total, orgânico e disponível e carbono orgânico total (COT) da camada de 0-10 cm de um Latossolo Vermelho distroférrico típico sob mata nativa e cultivado no sistema plantio direto (SPD) sem adição de fósforo

\begin{tabular}{clrl}
\hline Solo & P orgânico & P Mehlich-1 & COT \\
\hline & & $\mathrm{mg} \mathrm{kg}^{-1}$ & \\
Mata & $418 \mathrm{a}^{(1)}$ & $3,2 \mathrm{a}$ & $34,9 \mathrm{a}$ \\
SPD & $218 \mathrm{~b}$ & $3,1 \mathrm{a}$ & $20,3 \mathrm{~b}$
\end{tabular}

(1) Para cada variável, médias seguidas pela mesma letra, não diferem pelo teste $F(P<0,05)$. 
Quadro 2. Atividade de fosfatase ácida na camada de $0-10 \mathrm{~cm}$ de um Latossolo Vermelho distroférrico típico, considerando diferentes doses e épocas de aplicação fosfato solúvel, cultivado no sistema plantio direto

\begin{tabular}{|c|c|c|c|}
\hline \multicolumn{2}{|c|}{$\mathrm{P}_{2} \mathrm{O}_{5}$ aplicado } & \multirow{2}{*}{$\begin{array}{c}\mathrm{P}_{2} \mathrm{O}_{5} \\
\text { acumulado }\end{array}$} & \multirow{2}{*}{$\begin{array}{c}\text { Atividade de } \\
\text { fosfatase ácida } \\
\text { ( } \rho \text {-nitrofenol liberado) }\end{array}$} \\
\hline Inverno & Verão & & \\
\hline & $-k g h a^{-1}$ & - & $\mu \mathrm{g} \mathrm{h}^{-1} \mathrm{~g}^{-1}$ solo \\
\hline 0 & - & 0 & 589 \\
\hline 0 & 130 & 130 & 549 \\
\hline 0 & 260 & 260 & 550 \\
\hline 180 & - & 180 & 656 \\
\hline 360 & - & 360 & 584 \\
\hline 540 & - & 540 & 534 \\
\hline 720 & - & 720 & 606 \\
\hline 720 & 260 & 980 & 587 \\
\hline 720 & 520 & 1.240 & 639 \\
\hline
\end{tabular}

fosfatase ácida em solos de floresta também foi encontrada por Fernandes et al. (1998), demonstrando a sua importância no fornecimento de $\mathrm{P}$ às plantas em sistemas naturais.

No sol o cultivado, a atividade de fosfatase ácida permaneceu em torno de $600 \mu \mathrm{g}$ de $\rho$-nitrofenol $\mathrm{h}^{-1} \mathrm{~g}^{-1}$ de solo e não se detectou sua dimi nuição com o aumento da disponibilidade de $\mathrm{P}$ no solo (Quadro 2), comotambém anteriormente verificado por Badalucco et al. (1992). I sto pode ser atribuído à alta afinidade do $\mathrm{P}$ com os colóides minerais, especialmente os óxidos de ferro e alumínio, abundantes no solo estudado (Rheineimer et al., 2000), que adsorvem o $P$ e reduzem o seu efeito inibidor sobre a atividade de fosfatase.

A atividade de fosfatase ácida correlacionou-se com o Po ( $r=0,93$; $\mathrm{P}<0,05)$ e ambos, com o carbono orgânico total do solo ( $r=0,97$ e 0,94 , respectivamente; $P<0,05)$. A atividade desta enzima é mais influenciada pelo teor de Po do sol o que pel o fósforo total (Pt) e tem sido correlacionada com o teor de carbono ePo(Appiah \& Thomas 1982; Trasar-Cepeda \& Gil-Sotres, 1987). Assim, o Po pode ser disponibilizado para as plantas pela atividade de fosfatase ácida, mesmo com altas adições de fertilizantes fosfatados ao solo, mas sua importância deve ser maior em sistemas com baixo uso de insumos, por sua maior participação no atendimento da demanda de $P$ pelas culturas.

Em sistemas naturais, como florestas e campos nativos, o fornecimento de $P$ às plantas mostra-se dependente da ciclagem do P orgânico, principalmente em solos de regiões tropicais e subtropicais (Stewart \& Tiessen, 1987), como o aqui estudado. Neste estudo, observaram-se maiores teores de Po, Pm e atividade de fosfatase ácida na mata nativa, comparativamente ao solo cultivado, provavelmenteem razão da maior adição deresíduos, da sua qualidade, da menor variação detemperatura e umidade e da menor acidez do solo ( $\mathrm{pH}$ em água de 5,6, na mata nativa, e de 4,8, no experimento).

Assim, a disponibilidade de $P$ no sol o sob floresta e campos naturais ocorre por meio da atividade microbiana pela liberação de fosfatases, transformando formas de $\mathrm{P}$, de orgânicas em inorgânicas (Seeling \& Sasoski, 1993), condicionando o crescimento das plantas à ciclagem de Po da serapilheira. Atribui-se a biociclagem do $P$ nesses sistemas ao sincronismo entre a liberação de $\mathrm{P}$ dos resíduos orgânicos e a necessidade das plantas, reduzindo, dessa forma, a interferência da fase mineral

$\mathrm{O}$ acúmulo de $\mathrm{P}$ na biomassa microbiana, especialmente após aplicações recentes de fosfato, representa uma forma eficiente de armazenamento desse nutriente (Brookes et al., 1982; Hedley \& Stewart, 1982). No solo cultivado sob o sistema plantio direto, os microrganismos são importantes tanto na biociclagem como no armazenamento de $P$ em suas células, protegendo-o da adsorção pel os colóides do solo e, conseqüentemente, mantendo o P na forma disponível por mais tempo.

\section{CONCLUSÕES}

1. O fósforo contido na biomassa microbiana aumentou com a aplicação recente de fósforo e não foi influenciado pelo fósforo oriundo de aplicações anteriores.

2. A atividade de fosfatase ácida não foi influenciada pela adição defosfato ao sol o no sistema plantio direto.

3. O solo sob mata nativa apresentou maior atividade de fosfatase ácida, fósforo contido na biomassa microbiana e fósforo orgânico em relação ao sol o cultivado.

\section{AGRADECIMENTOS}

Ao pesquisador J oão Becker, pela atenção, disponibilidade e concessão da área experimental, que serviu de base para este trabalho.

\section{LITERATURA CITADA}

APPIAH, M.R. \& THOMAS, R.L. I nositol phosphate and organic phosphorus contents and phosphatase activity of some Canadian and Ghanaian soils. Can. J. Soil Sci., 21:31-38, 1982. 
BADALUCCO, L.; GREGO, S.; DELL'ORCO, S. \& NANNIPIERI, $P$. Effect of liming on some chemical, biochemical, and micobiological properties of acid soils under spruce (Picea abies L.). Biol. Fertil. Soils, 14:76-83, 1992.

BOWMAN, R.A.; REEDER, J.D. \& LOBER, R.W. Changes in soil properties in a central plains rangeland soil after 3, 20 and 60 years of cultivation. Soil Sci., 150:851-857, 1990.

BROOKES, P.C.; POWLSON, D.S. \& JENKINSON, D.S. Measurement of microbial biomass phosphorus in soil. Soil Biol. Biochem., 14:319-329, 1982.

CHAUHAN, B.S.; STEWART, J.W.B. \& PAUL, E.A. Effect of carbon additions on soil labile inorganic, organic and microbially help phosphate. Can. J. Soil Sci., 59:387-396, 1979.

CLHARHOLM, M. Microbial biomass $P$, labile $P$ and acid phosphatase activity in the humus layer and spruce forest, after repeated additions of fertilizers. Biol. Fertil. Soils, 16:287-292, 1993.

COMISSÃO DE FERTILIDADE DO SOLO - CFC-RS/SC. Recomendações de adubação e calagem para os estados do Rio Grande do Sul e Santa Catarina. 3.ed. Passo Fundo, SBCS/NRS/EMBRAPA/CNPT, 1995. 224p.

DORAN, J.W. Soil microbial and biochemical changes associated with reduced tillage. Soil Sci. Soc. Am. J ., 44:765-771, 1980.

FERNANDES,A.R.;FURTINI NETO,A.E.; CURI, N.; LIMA,J .M. $\&$ GUEDES, G.A.A. Fósforo e atividade de fosfatase em dois solos sob diferentes condições de uso. Pesq. Agropec. Bras., 33:1159-1170, 1998.

GUERRA, J.G.M.; FONSECA, M.C. \& ALMEIDA, D.L.; DEPOLLI, H. \& FERNANDES, M.S. Conteúdo de fósforo da biomassa microbiana de um solo cultivado com Brachiara decumbens Stapf. Pesq. Agropec. Bras., 30:543-551, 1995.

GUGGENBERGER, G.; HAUMAIER, L. \& THOMAS, R.J . Assessing the organic phosphorus status of an oxisol under tropical pastures following native savanna using ${ }^{31}$ P NMR spectroscopy. Biol. Fertil. Soils, 23:332-339, 1996.

HARRISON, A.F. Relations between intensity of phosphatase activity and physico-chemical properties in woodland soils. Soil Biol. Biochem., 15:93-99, 1983.

HEDLEY, M.J . \& STEWART, J.W.B. Method to measure microbial phosphate in soils. Soil Biol. Biochem., 14:377-385, 1982.

LUKITO, H.P.; KUONO, K.\& ANDO, T. Phosphorus requeriments of microbial biomass in a regosol and an andosol. Soil Biol. Biochem., 30:865-872, 1998.

MAGID, J .;TIESSEN, H \& \& CONDRON, L.M. Dynamics of organic phosphorus in soils under natural and agricultural ecosystems. In: PICCOLO, A., ed. Humic substances in terrestrial systems. Amsterdan, Eslsevier, 1996. p.429-466.
MOREL, C.; TIESSEN, H.\& STEWART, J.W.B. Correction for Psorption in the measurement of soil microbial biomass $\mathrm{P}$ by $\mathrm{CHCl}_{3}$ fumigation. Soil. Biol. Biochem., 28:1699-1706, 1996.

OLSEN, S.R. \& SOMMER, L.E. Phosphorus. In: PAGE, A.L.; MILLER, R.H. \& KEENEY, Q.R., eds. Methods of soil analysis, Part 2. Chemical and microbiological properties. 2.ed. Madison, American Society of Agronomy, 1982. p.403430. (Agronomy Monograph, 9)

POTTKER, D. Efeito do tipo de solo, tempo de cultivo eda calagem sobre a mineralização da matéria orgânica em solos do Rio Grande do Sul. Porto Alegre, Universidade Federal do Rio Grande do Sul, 1977. 128p. (Tese de Mestrado)

RHEINHEIMER, D.S.; ANGHINONI, I. \& CONTE, E. Fósforo da biomassa microbiana em solos sob diferentes sistemas de manejo. R. Bras. Ci. Solo, 24:589-597, 2000.

ROSS, D.J .; SPEIR, T.W.; KETTLES, H.A. \& MACKAY, A.D. Soil microbial biomass, $\mathrm{C}$ and $\mathrm{N}$ mineralization and enzymes activities in a hill pasture: influence of season and slowrelease $\mathrm{P}$ and sorption fertilizer. Soil Biol. Biochem., 27:1431-1443, 1995

SAFFIGNA, P.G.; POWLSON, D.S.; BROOKES, P.C. \& TOMAS, G.A.. Influence of sorghum residues and tillage on soil organic matter and soil microbial biomass in an Australian vertisol. Soil Biol. Biochem., 21:759-765, 1989.

SEELING, B. \& ZASOSKI, R.J. Microbial effects in maintaining organic and inorganic solution phosphorus concentrations in a grassland top soil. Plant Soil, 148:227-284, 1993.

STEWART, J.W.B. \& TIESSEN, H. Dynamics of soil organic phosphorus. Biochem., 4:41-60, 1987

TABATABAI, M.A. \& BREMNER, J.M. Use of p-nitrophenyl phosphate for assay of soil phosphatase activity. Soil Biol. Biochem., 1:301-307, 1969.

TEDESCO, M.J .; GIANELLO, C.; BISSANI, C.A.; BOHNEN, H. \& VOLKWEISS, S.J. Análises de solo, plantas e outros materiais, 2.ed. Porto Alegre, Universidade Federal do Rio Grande do Sul, 1995. 174p. (Boletim Técnico, 5)

TATE, K.R. The biological transformation of $P$ in soil. Plant Soil, 76:245-256, 1984.

TIESSEN, H.; STEWART, W.B. \& MOIR, J .O. Changes in organic and inorganic phosphorus composition of two grassland soils and their particle size fractions during 60-90 years of cultivation. J. Soil Sci., 34:815-823, 1983.

TRASAR-CEPEDA, M.A. \& GIL-SOTRES, F. Phosphatase activity in acid high organic matter soils in Galicia (NW Spain). Soil Biol. Biochem., 19:281-287, 1987.

ZHANG, T.Q.; MacKENZIE, A.F. \& SAURIOL, F. Nature of soil organic phosphorus as affected by long-term fertilization under continuos corn (Zea mays L.): a 31 P NMR study. Soil Sci., 164:662-670, 1999. 